\title{
A stable liquid-liquid extraction system for clavulanic acid using polymer-based aqueous two-phase systems
}

\author{
Jorge F.B. Pereira ${ }^{\mathrm{a}, \mathrm{b}}$, Valéria C. Santos ${ }^{\mathrm{c}}$, Hans-Olof Johansson ${ }^{\mathrm{d}}$, José A.C. Teixeira ${ }^{\mathrm{b}}$, Adalberto Pessoa Jr. ${ }^{\mathrm{c}, *}$ \\ ${ }^{a}$ Chemistry Department, CICECO, University of Aveiro, 3810-193 Aveiro, Portugal \\ ${ }^{\mathrm{b}}$ IBB-Institute for Biotechnology and Bioengineering, Center for Biological Engineering, Universidade do Minho, Campus de Gualtar, 4710-057 Braga, Portugal \\ ${ }^{\mathrm{c}}$ Department of Biochemical and Pharmaceutical Technology, University of São Paulo, Avenida Prof. Lineu Prestes 580, Bl. 16, 05508-900 São Paulo, SP, Brazil \\ ${ }^{\mathrm{d}}$ Department of Pure and Applied Biochemistry, University of Lund, P.O. Box 124, SE-221 00 Lund, Sweden
}

\section{A R T I C L E I N F O}

\section{Article history:}

Received 30 March 2012

Received in revised form 9 July 2012

Accepted 4 August 2012

Available online 11 August 2012

\section{Keywords:}

Clavulanic acid

Aqueous two-phase systems

Poly(ethylene glycol)

Poly(acrylic acid)

Streptomyces clavuligerus

\begin{abstract}
A B S T R A C T
The partitioning of Clavulanic Acid (CA) in a novel inexpensive and stable aqueous two-phase system (ATPS) composed by poly(ethylene glycol) (PEG) and sodium polyacrylate (NaPA) has been studied. The aqueous two-phase systems are formed by mixing both polymers with a salt $\left(\mathrm{NaCl}\right.$ or $\left.\mathrm{Na}_{2} \mathrm{SO}_{4}\right)$ and an aqueous solution of CA. The stability of CA on the presence of both polymers was investigated and it was observed that these polymers do not degrade the biomolecule. The effect of PEG-molecular size, polymer concentrations on the commercial CA partitioning has been studied, at $25^{\circ} \mathrm{C}$. The data showed that commercial CA was preferentially partitioned for the PEG-rich phase with a partition coefficient $\left(K_{\mathrm{CA}}\right)$ between 1 and 12 in the PEG/NaPA aqueous two phase systems supplemented with $\mathrm{NaCl}$ and $\mathrm{Na}_{2} \mathrm{SO}_{4}$. The partition to the PEG phase was increased in the systems with high polymer concentrations. Furthermore, $\mathrm{Na}_{2} \mathrm{SO}_{4}$ caused higher CA preference for the PEG-phase than $\mathrm{NaCl}$. The systems having a composition with 10 wt.\% of PEG4000, 20 wt.\% of NaPA8000 and 6 wt.\% of $\mathrm{Na}_{2} \mathrm{SO}_{4}$ were selected as the optimal ones in terms of recovery of CA from fermented broth of Streptomyces clavuligerus. The partitioning results $\left(K_{\mathrm{CA}}=9.15 \pm 1.06\right)$ are competitive with commercial extraction methods of $\mathrm{CA}$ $\left(K_{\mathrm{CA}}=11.91 \pm 2.08\right)$ which emphasizes that the system $\mathrm{PEG} / \mathrm{NaPA} / \mathrm{Na}_{2} \mathrm{SO}_{4}$ can be used as a new process to CA purification/concentration from fermented broth.
\end{abstract}

(c) 2012 Elsevier B.V. All rights reserved.

\section{Introduction}

Clavulanic Acid (CA) is a bicyclic $\beta$-lactam compound made up of a $\beta$-lactam ring and an oxazolidine ring (Fig. 1) [1]. Its application together with penicillin has proven to be successful against bacteria with resistance to $\beta$-lactam antibiotics and is thus clinically and economically interesting [2-4]. Currently, potassium clavulanate is used in conjunction with amoxycillin and prescribed as co-amoxiclav (Augmentin $\left({ }^{\mathrm{TM}}\right)$ ) or with ticarcillin as Timentin $\left({ }^{\mathrm{TM}}\right)$ [5]. Furthermore, recent studies have shown that CA possesses strong central nervous system modulating effects [6,7] and findings suggest that this drug can act as a neuroprotective agent in Parkinson's models in vivo $[7,8]$.

Industrially, CA is produced by batch fermentation of Streptomyces clavuligerus and its process of isolation and purification is a relatively complex downstream process. Traditionally, the first step of purification consists in medium clarification by filtration or centrifugation, followed by either adsorption or liquid-liquid extraction with organic solvents and further purification by anion-exchange chromatography or other chromatographic tech-

\footnotetext{
* Corresponding author. Tel.: +55 11 30913862; fax: +55 1138156386 .

E-mail address: pessoajr@usp.br (A. Pessoa Jr.).
}

niques [4,9]. However, this drug does not have any markedly hydrophobic group, and like other $\beta$-lactam compounds, CA in its crude form is very unstable chemically, due to the susceptibility of the carbonyl group linked to the $\beta$-lactam ring to acidic $\left(\mathrm{H}^{+}\right)$or alkaline $\left(\mathrm{OH}^{-}\right)$-catalyzed attack by water molecules, this making purification yields generally low [10]. Thus, the development of more efficient and cost-effective separation and purification processes is crucial to improve process efficiency and economics, keeping the required high standards of quality for market approval [11].

In the search for alternative methods, liquid-liquid extractions carried out in various types of aqueous two-phase complex-fluid systems have been investigated for bio-separation needs [12]. Extraction with aqueous two-phase systems (ATPSs) is a technique used to separate biological, sensitive macromolecules, namely proteins [13], enzymes [14], antibiotics [15], etc. ATPS can be formed by mixing two water-soluble polymers, which have a mutual repulsion or by mixing one semi-hydrophobic (like PEG) polymer with salt, above a critical concentration [16,17]. The mixture will then separate into two immiscible phases, where the light phase (top phase) is rich in one polymer and the heavy one (bottom phase) is rich in the second polymer or the salt. A more or less sharp interface exists between the top and bottom phases [18]. 


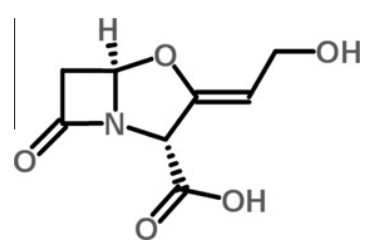

Fig. 1. Chemical structure of Clavulanic Acid (CA).

Despite some of the advantages of conventional biphasic systems composed of polymer and inorganic salts (i.e. low interfacial tension, fast and high phase separation rates, low cost), [19], the presence of high amounts of the inorganic salts leads to a significant increase of CA losses [20]. In conventional PEG/salt systems the phase formation is directly related to the salting out effect and only hydrophilic salts, such as, phosphate, sulfate, citrate, can be used for ATPS formation [21]. Recently, it was reported that sodium polyacrylate (NaPA) and poly(ethylene glycol) (PEG) can form an ATPS [22,23]. These new polymer-polymer aqueous systems, abbreviated to PEG-NaPA, separate relatively fast and have relatively low viscosity in contrast to other traditional polymer-polymer aqueous two-phase systems. The two polymers PEG and NaPA are harmless, relatively inexpensive and easily handled. Chemically, PEG is an uncharged polymer whereas NaPA is a strongly negatively charged polymer. Thus, to form the aqueous two-phase system a minimum concentration of salt is necessary, due to entropy penalty upon compartmentalization of counter ions. Since the NaPA is strongly negative it will have strong repulsive interaction with charged biomolecules although the presence of salt may screen the electrostatic interactions to a similar level of strength as entropic and hydrophobic forces [24]. Recently, some biomolecules such as green fluorescent protein (GFP) [21], hemoglobin, lysozyme and glucose-6-phosphate dehydrogenase [24] were partitioned with retained activity using the PEG/NaPA aqueous two-phase systems.

The CA partitioning using ATPS obtained by PEG and salt solutions have been studied, and there are some reports in the literature that explore this approach $[3,4,9,25,26]$, However, the CA partition/ recovery using polymer-polymer aqueous two phase systems composed by PEG and NaPA was investigated for the first time in this work. Since $C A$ is negatively charged a repulsion between this drug and NaPA is expected, causing an improved recovery of CA in the PEG phase. Thus, in this work CA partitioning was studied in different PEG/NaPA systems. Initially, commercial CA was used to optimize the partition of biomolecule. In the second part of the study, the partitioning of CA from fermented broth of S. clavuligerus was studied using the optimized PEG/NaPA ATPS. The aim of this study was to develop an alternative, inexpensive and stable method compared to traditional ones used for CA recovery.

\section{Experimental}

\subsection{Materials}

Poly(ethylene glycol) (PEG) 2000, 4000 and $6000 \mathrm{~g} \mathrm{~mol}^{-1}$ were purchased from Merck (Hohenbrunn, Germany). Na-poly(acrylate) (NaPA) $8000 \mathrm{~g} \mathrm{~mol}^{-1}(45 \% \mathrm{w} / \mathrm{w})$ was purchased from SigmaAldrich (St. Louis, MO, USA) as a 45 wt.\% aqueous solution. Three different sources of CA were used, specifically CA produced by $S$. clavuligerus ATCC 27064 fermentation, pharmaceutical grade (54\% purity) from Galena (Campinas, Brazil) and commercial CA (potassium salt) from Sigma-Aldrich (St. Louis, MO, USA) (99\% purity). Imidazole used in CA determinations was provided by SigmaAldrich (St. Louis, MO, USA). Bicinchoninic acid assay kit was obtained from Sigma Chemicals (St. Louis, MO, USA). All the other reagents were of analytical grade and were used as received. All the solutions were prepared in Mcllvaine's buffer, $\mathrm{pH}$ 6.5, consisting of $1.38 \mathrm{mM}$ citric acid and $5.3 \mathrm{mM}$ disodium phosphate in water purified by filtration through a Millipore Milli-Q ionexchange system (Bedford, MA, USA).

\subsection{Microorganism maintenance and fermentations}

S. clavuligerus ATCC 27064 was kindly provided by the Microorganism Collection of the Department of Antibiotics of the Federal University of Pernambuco, Recife, PE, Brazil. The microorganism was maintained frozen at $-70^{\circ} \mathrm{C}$ with glycerol in a cryotube. A thick spore suspension contained in cryotube was transferred to $25 \mathrm{~mL}$ of reactivation medium in $250 \mathrm{~mL}$-Erlenmeyer flasks. After incubation in an orbital shaker at $28^{\circ} \mathrm{C}$ and $250 \mathrm{rpm}$ for $24 \mathrm{~h}, 2.5 \mathrm{~mL}$ of this suspension were added to $22.5 \mathrm{~mL}$ of fermentation medium and again incubated in an orbital shaker under the same conditions.

For fermentations, $5.0 \mathrm{~mL}$ of the resulting cell suspension were added to $45 \mathrm{~mL}$ of fermentation medium in $500 \mathrm{~mL}$-Erlenmeyer flasks and incubated in orbital shaker under the same conditions for $120 \mathrm{~h}$. After fermentation, the broth was centrifuged at $3720 \mathrm{~g}$ for $15 \mathrm{~min}$ at $5^{\circ} \mathrm{C}$ in a centrifuge, model BR4i (Jouan, Saint Herblain, France). The supernatant was frozen in ultrafreezer at $-70{ }^{\circ} \mathrm{C}$ to be used in the partitioning studies.

\subsection{Media composition}

To get vegetative cell from the spores, we used the reactivation medium proposed by Ortiz et al. [27], having the following composition ( $\mathrm{g} \mathrm{L}^{-1}$ deionised water): glycerol (15), bacteriologic peptone (10), malt extract (10), $\mathrm{K}_{2} \mathrm{HPO}_{4}(2.5), \mathrm{MgSO}_{4} \cdot 7 \mathrm{H}_{2} \mathrm{O}(0.75), 3-(\mathrm{N}-$ morpholino) propanesulfonic acid (MOPS) (21); and $\left(\mathrm{mg} \mathrm{L}^{-1}\right)$ : $\mathrm{MnCl}_{2} \cdot 4 \mathrm{H}_{2} \mathrm{O}$ (1.0), $\mathrm{FeSO}_{4} \cdot 7 \mathrm{H}_{2} \mathrm{O}$ (1.0), $\mathrm{ZnSO}_{4} \cdot 7 \mathrm{H}_{2} \mathrm{O}$ (1.0).

The medium proposed by Ortiz et al. [27], where soy flour was replaced by soy flour extract, was used either as inoculum or fermentation medium. It was composed of $\left(\mathrm{g} \mathrm{L}^{-1}\right.$ deionised water): glycerol (10), $\mathrm{K}_{2} \mathrm{HPO}_{4}$ (1.2), MOPS (21), soy oil (23), extract of soy flour (20); and ( $\left.\mathrm{mg} \mathrm{L}^{-1}\right)$ : $\mathrm{MnCl}_{2} \cdot 4 \mathrm{H}_{2} \mathrm{O}(10), \mathrm{FeSO}_{4} \cdot 7 \mathrm{H}_{2} \mathrm{O}$ (10), $\mathrm{ZnSO}_{4} \cdot 7 \mathrm{H}_{2} \mathrm{O}$ (10).

Both media had the $\mathrm{pH}$ adjusted to 6.8 with $\mathrm{NaOH} 5.0 \mathrm{M}$ and were autoclaved at $121^{\circ} \mathrm{C}$ for $15 \mathrm{~min}$.

\subsection{Evaluation of clavulanic acid stability at different types and concentrations of polymer}

CA stability was evaluated for PEG 2000, 4000 and $6000 \mathrm{~g} \mathrm{~mol}^{-1}$ and NaPA $8000 \mathrm{~g} \mathrm{~mol}^{-1}$. For each polymer, solutions were prepared at 5 and 15 wt.\%. CA was added in each solution from a concentrated CA stock solution $\left(300 \mathrm{mg} \mathrm{L}^{-1}\right)$, reaching an initial CA concentration of $30 \mathrm{mg} \mathrm{L}^{-1}$. The solutions were then homogenized in orbital shaker, model 400110 (Branstead/Thermolyne, Dubuque, IA, USA), at $8 \mathrm{rpm}$ for $5 \mathrm{~min}$ at room temperature $\left(25^{\circ} \mathrm{C}\right)$ and kept in a bath, model 521/2DE (New Ethics, Vargem Grande Paulista, SP, Brazil), during $3 \mathrm{~h}$. Aliquots of the solutions were withdrawn at time intervals of $0,1,2$ and $3 \mathrm{~h}$ and the concentration of nondegraded clavulanic acid was determined as described below. All experiments were performed in triplicate, and the standard deviations and confidence intervals calculated. The limit of significance for the statistical analysis was resulting in a confidence interval of $95 \%$. The percentage of CA present in the solution was calculated according to the following equation:

$\mathrm{CA}(\%)=\frac{\mathrm{CA}_{\mathrm{SOL}}}{\mathrm{CA}_{\mathrm{INI}}} \times 100$

where CA (\%) represents the percentage of CA which was resistant to the polymer-treatment, $\mathrm{CA}_{\mathrm{SOL}}$ and $\mathrm{CA}_{\mathrm{INI}}$ are the $\mathrm{CA}$ concentration 
( $\mathrm{mg} \mathrm{L}^{-1}$ ) after the polymer-treatment and the initial CA concentration, respectively.

\subsection{Partitioning of clavulanic acid in the PEG/NaPA ATPS}

The PEG/NaPA ATPS were prepared in Mcllvaine buffer pH 6.5 either with $\mathrm{NaCl}$ (1.05 wt.\%) or $\mathrm{Na}_{2} \mathrm{SO}_{4}$ (6.00 wt.\%), and varying the molecular weight and concentrations of PEG and the concentration of NaPA. The components of the system were added to $15 \mathrm{~mL}$ glass tubes by weighing to obtain a total mass of $10.0 \mathrm{~g}$. To investigate the influence of different PEG molecular weight $\left(2000,4000\right.$ and $\left.6000 \mathrm{~g} \mathrm{~mol}^{-1}\right)$ on CA partition, preliminary experiments of CA partitioning were carried out using pharmaceutical grade $C A$ at a concentration of $300 \mathrm{mg} \mathrm{L}^{-1}$. The polymer concentrations were $6 \mathrm{wt} . \%$. According to the preliminary results, PEG4000 was chosen to be used in the following experiments, where the PEG and NaPA concentration was changed in order to optimize the CA partitioning. The second part of this work consisted on the CA extraction directly from the culture supernatant using the PEG/NaPA aqueous two-phase system optimized on the first stage of the work. In this stage, the concentration of PEG and NaPA was fixed respectively at 10 and $20 \mathrm{wt}$.\%, to evaluate the extraction of pure commercial CA, and CA from the culture supernatant. In this case, the CA concentration varied between 255 and $416 \mathrm{mg} \mathrm{L}^{-1}$ depending on the fermentation conditions.

All the solutions were mixed at $8 \mathrm{rpm}$ during $20 \mathrm{~min}$ at room temperature in an end-to-end mixer (Branstead/Thermolyne, Dubuque, IA, USA). The tubes were then put on a water-bath, model 521/2DE (New Ethics, Vargem Grande Paulista, SP, Brazil), at $25^{\circ} \mathrm{C}$. The formation of two-phase systems was generally accomplished within 2 min but the systems were left standing in the water-bath at least $5 \mathrm{~min}$ after phase separation. After the phase settling, samples of upper and lower phases were collected carefully, using Pasteur-pipettes, and the concentration of CA was determined in both phases.

The partitioning behaviour of CA in PEG/NaPA ATPS was quantified either in terms of the partition coefficient, $K_{\mathrm{CA}}$ :

$K_{\mathrm{CA}}=\frac{C_{\mathrm{CAT}}}{C_{\mathrm{CAB}}}$

or of the CA yield in the top phase, $\eta_{\mathrm{CA}}$ :

$\eta_{\mathrm{CA}}=\frac{V_{T} C_{T}}{V_{I} C_{I}} \times 100$

where $C$ and $V$ are the CA concentration $\left(\mathrm{mg} \mathrm{L}^{-1}\right)$ and the volume of the system $(L)$, respectively, while the subscripts $T, B$ and $I$ do refer to the top (PEG-rich phase) phase, bottom (NaPA-rich phase) phase and initial phase, respectively.

The partitioning behaviour was also checked in terms of the mass balance, $\mathrm{MB}_{\mathrm{CA}}$, which is defined as:

$\mathrm{MB}_{\mathrm{CA}}=\frac{V_{T} C_{T}+V_{B} C_{B}}{V_{I} C_{I}} \times 100$

The volumetric phase ratio, $\mathrm{R}$, was calculated and defined as:

$R=\frac{V_{T}}{V_{B}}$

The partition coefficient of total proteins $\left(K_{P}\right)$ is also evaluated according to Eq. (6), as follows:

$K_{P}=\frac{C_{\mathrm{PT}}}{C_{\mathrm{PB}}}$

where $C_{\mathrm{PT}}$ and $C_{\mathrm{PB}}$ are the total proteins concentration $\left(\mathrm{g} \mathrm{L}^{-1}\right)$ in the top (PEG-rich phase) and bottom (NaPA-rich phase) phase, respectively.

\subsection{Analytical methods}

\subsubsection{Determination of the concentration of clavulanic acid}

The CA concentration was determined by measuring the increase in the optical density at $312 \mathrm{~nm}$ resulting from the release of the product [1-(8-hydroxy-6-oxo-4-azooct-2-enol)-imidazole] of the reaction between CA and imidazole [28]. The optical density was carried out by spectroscopy using a SHIMADZU UV-1650PC (Shimadzu, Kyoto, Japan) spectrophotometer at $312 \mathrm{~nm}$ and using a calibration curve previously established.

\subsubsection{Determination of total protein concentration}

Total protein concentration (TP) was determined using the bicinchoninic acid method (BCA), compatible with polymers. Samples of $100 \mu \mathrm{L}$ containing proteins and $2 \mathrm{~mL}$ of the BCA working reagent, prepared according to the manufacturer's instructions, were added to a test tube. After $30 \mathrm{~min}$ the optical density at $562 \mathrm{~nm}$ was determined in spectrophotometer using deionized water as blank. A calibration curve correlating optical density with protein concentration was determined using bovine serum albumin (BSA) solutions from 0 to $1 \mathrm{mg} \mathrm{mL}^{-1}$.

\section{Results and discussion}

\subsection{Evaluation of clavulanic acid stability in different polymers at different concentrations of polymer}

CA in its crude form is chemically unstable, and its stability in a wide range of $\mathrm{pH}$, temperature, types and concentrations of different salts has been investigated [20,29-33].

Recently the stability of CA to different conditions of $\mathrm{pH}$, temperature and type and salt concentration was studied [20]. It was demonstrated that the best conditions for CA stability are in $\mathrm{pH}$ range of 6.0-7.2 and $25^{\circ} \mathrm{C}$. Furthermore, it was demonstrated that the addition of high concentrations of salts to the aqueous solution of antibiotic increased its degradability. These facts were considered in the search for the optimal purification process of CA with PEG/NaPA two-aqueous phase systems. PEGs with different molecular weight $\left(2000,4000\right.$ and $\left.6000 \mathrm{~g} \mathrm{~mol}^{-1}\right)$ and 5 or $15 \mathrm{wt}$.\% were mixed with $\mathrm{CA}$ in an aqueous solution at pH 6.5 and $25^{\circ} \mathrm{C}$. Samples were withdrawn every hour (during $3 \mathrm{~h}$ ) and the ratio (CA (\%)) between concentration of $\mathrm{CA}$ at the defined time $\left(C_{\mathrm{SOL}}\right)$ and initial concentration of $C A\left(C_{I}\right)$ was quantified and presented in Fig. 2. The stability of CA was evaluated up to $3 \mathrm{~h}$ of presence in the ATPS. The time for the PEG/NaPA systems to settle into two clear phases is less than $20 \mathrm{~min}$.

The results in Fig. 2 show that addition of different types and concentrations of PEG do not affect the CA stability. These results were expected, since PEG is relatively inert [34].

Following the same approach the CA stability in the presence of NaPA with molecular weight of $8000\left(\mathrm{~g} \mathrm{~mol}^{-1}\right)$, at two different concentrations (5 and $15 \mathrm{wt} . \%$ ), was studied during $3 \mathrm{~h}$. The CA (\%) was measured and presented in Fig. 3.

Similarly to PEG results, NaPA polymer does not affect the stability. Hughes and Lowe [35] affirmed that sodium polyacrylate is an inert polymer, which is in close accordance to the expected.

Salts such as $\mathrm{NaCl}$ and $\mathrm{Na}_{2} \mathrm{SO}_{4}$ are added to NaPA/PEG twophase systems $[21,24,36]$ to promote phase separation. The stability of $\mathrm{CA}$ in presence of $\mathrm{NaCl}$ or $\mathrm{Na}_{2} \mathrm{SO}_{4}$ was performed by incubating $\mathrm{CA}$ for $6 \mathrm{~h}$ in salt solutions having the concentrations of 0.1 and $0.5 \mathrm{M}$ [20]. For both salts, the loss of CA stability upon increase in salt concentration from 0.1 to $0.5 \mathrm{M}$ was relatively moderate. The fraction of degraded CA increased from about $4 \%$ to $5 \%$ with $\mathrm{NaCl}$ and from $8 \%$ to $9 \%$ with $\mathrm{Na}_{2} \mathrm{SO}_{4}$. 


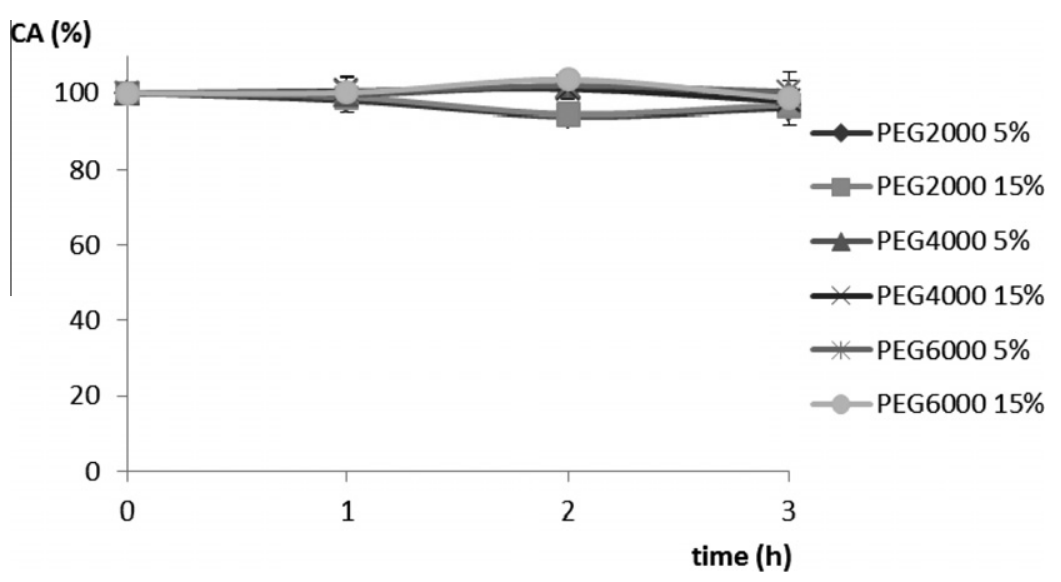

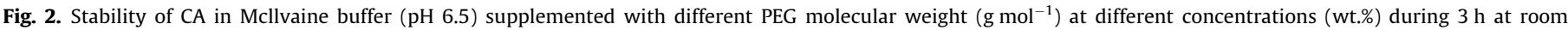
temperature at $25{ }^{\circ} \mathrm{C}$. The error bars represent $95 \%$ confidence limits for measurements.

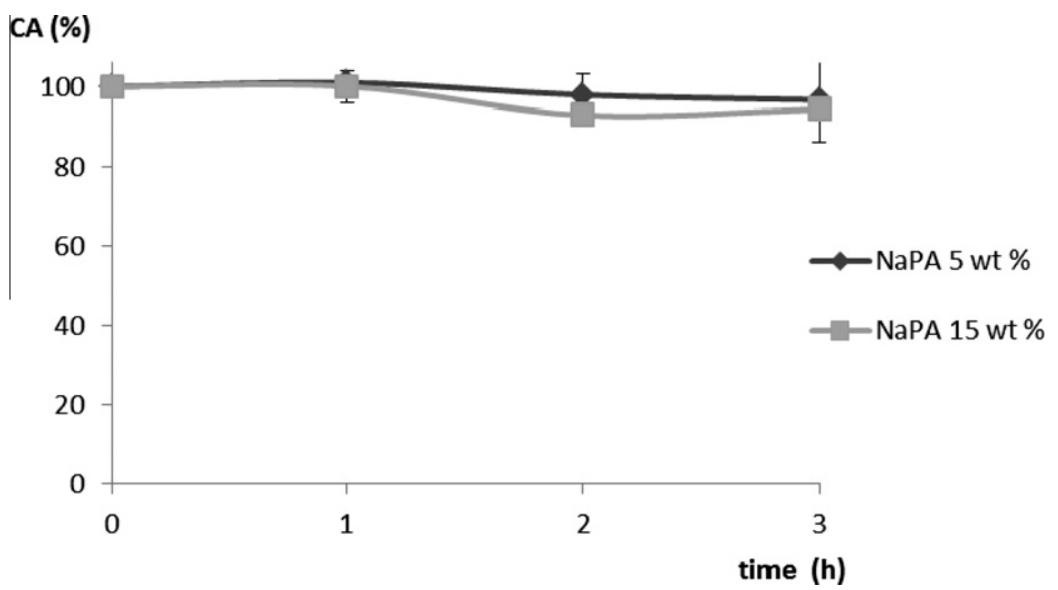

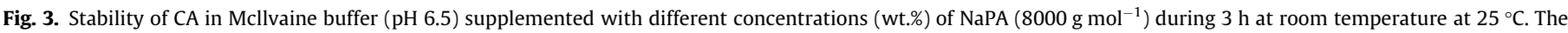
error bars represent $95 \%$ confidence limits for measurements.

Thus, these results of stability tests show that PEG/NaPA systems are compatible with CA.

3.2. Preliminary Studies of CA partition with PEG/NaPA aqueous twophase systems

The partition of CA was experimentally determined for PEG/ $\mathrm{NaPA}$ aqueous two-phase systems at $25^{\circ} \mathrm{C}$ and a $\mathrm{pH}$ range between 6.5 and 7.2 , with either 1.05 wt.\% $\mathrm{NaCl}$ or 6.00 wt.\% $\mathrm{Na}_{2} \mathrm{SO}_{4}$. The latter salt concentrations were previously found to promote suitable PEG/NaPA systems [36]. To understand the influence of PEG molecular weight on the partition of CA, preliminary studies combining 4 different PEGs (2000, 4000, 8000 and 10,000 $\mathrm{g} \mathrm{mol}^{-1}$ ) and $\mathrm{NaPA}$ with $8000 \mathrm{~g} \mathrm{~mol}^{-1}$ were performed. Aqueous two-phase systems using $6 \mathrm{wt} . \%$ of both polymers and addition of respective salts were prepared. The partition coefficient of CA was measured $\left(K_{\mathrm{CA}}\right)$ and the respective results are presented in Fig. 4.

The partition coefficient results $\left(1.47 \pm 0.05<K_{\mathrm{CA}}<1.83 \pm 0.03\right)$ described in Fig. 4 shows that this parameter is not significantly affected by the presence of different electrolytes (inorganic salts) and different PEG molecular weights. The system PEG2000/ $\mathrm{NaPA} 8000 / \mathrm{NaCl}$ does not form two-aqueous phases (since the mixing point is below the binodal) for the conditions evaluated. The constant partitioning of CA with changing conditions is remarkable since the position of the binodal differs significantly in the studied systems [36]. Top-phases containing PEGs with large molecular size exert a stronger entropic repulsion to all partitioned molecules. However, the concentration of PEG is also increased in the top-phase for systems with large PEG molecular weight. The conclusion of these results is that enthalpic and entropic changes upon CA compensate each other upon changing phase composition. PEG is an uncharged polymer and NaPA is a strongly negatively charged polymer, thus in order for them to separate with lower concentration of polymers (1-10 wt.\%), a minimum concentration of salt is necessary, due to entropy penalty upon compartmentalization of counter ions [24,37]. Since the NaPA is strongly negative, it will have a strong repulsive electrostatic interaction with anionic biomolecules [21]. CA has a negative charge at neutral $\mathrm{pH}\left(\mathrm{p} K_{\mathrm{a}}=2.3-2.7\right.$ [9]), leading to a relative preference for the PEG-rich phase in the PEG/NaPA system. The partitioning of the charged CA from the NaPA- to the PEG-rich phase is followed by a compensatory transfer of anions from the PEG- to NaPA-rich phase to maintain the electroneutrality. This process is thermodynamically favorable, since the ions of inorganic salts have a higher energy than the relatively large monovalent CA in the PEG-rich phase due to the more hydrophobic environment in the top PEG-rich phase in comparison to the bottom PEG-poor phase [21].

The preliminary partition coefficients of CA where similar for all different PEG molecular weight, thus in the following tests the system that combines PEG4000/NaPA8000 aqueous two-phase systems with addition of $\mathrm{Na}_{2} \mathrm{SO}_{4}$ or $\mathrm{NaCl}$ was used. 


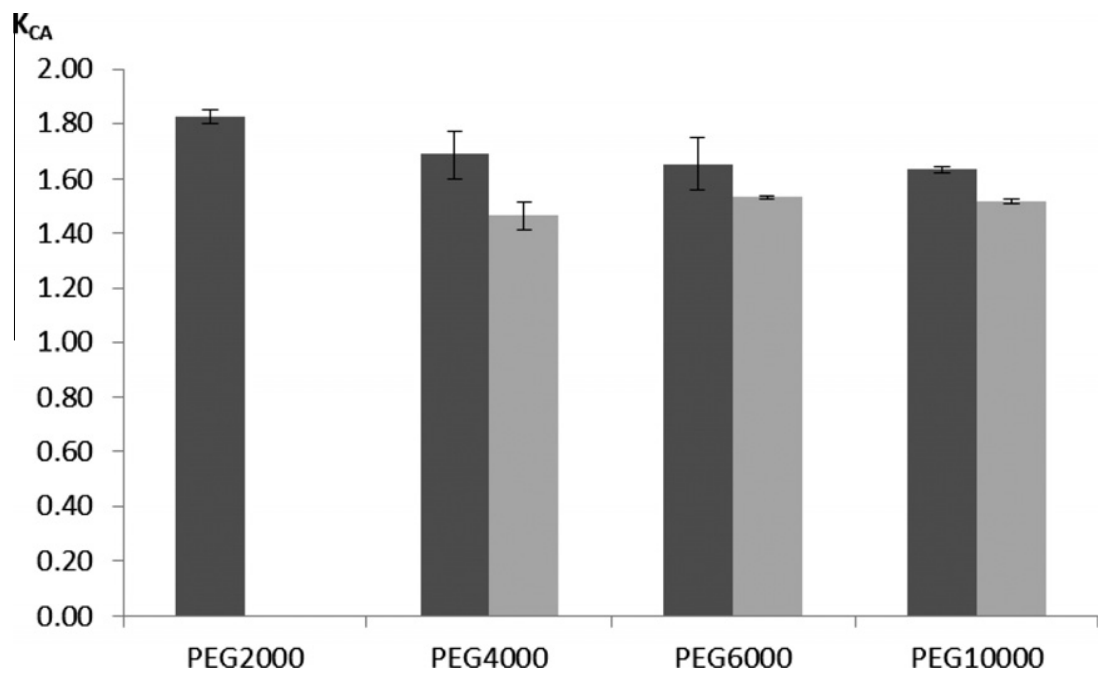

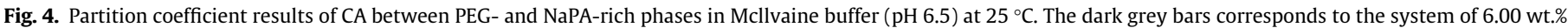
of $\mathrm{Na}_{2} \mathrm{SO}_{4}$ and light grey bars corresponds to system with addition of $1.05 \mathrm{wt} \%$ of $\mathrm{NaCl}$ The error bars represent $95 \%$ confidence limits for measurements.

\subsection{CA partition with $\mathrm{PEG} / \mathrm{NaPA} / \mathrm{NaCl}$ aqueous two-phase systems}

The optimization of CA partitioning in PEG4000/NaPA8000/ $\mathrm{NaCl}$ aqueous two-phase systems was based on the phase diagrams described by Johansson et al. [36]. The experimental points of CA partition were obtained changing the mass fraction of both polymers. The selected experimental data and the respective phase diagram are presented in Fig. 5.

As depicted in Fig. 5, for each point the values of CA partition coefficient, mass balance, volumetric ratio and yield were measured and the respective values presented in the Table 1 . Initially a first scan was performed (up to point 7) in order to evaluate the trend of CA partition. This initial survey has shown that an increase on the polymer concentration leads also to an increase on the partition coefficient. Thus a second investigation was performed, increasing the PEG and NaPA concentration at the same proportions (point 7-14) in order to obtain the highest values of $K_{\text {CA. }}$. However, for high concentrations of polymer, the high viscosity of the system makes the homogenization and the following phase separation difficult. This effect limited the maximum polymer concentration to $20 \mathrm{wt}$.\% of both polymers (point 14). In order to find the best partition coefficient, mixing points around the maximum concentration (15-20 wt.\%) were selected. These experiments were performed in triplicate and the respective errors were estimated.

The MB values of the aqueous systems studied show that no significant losses of CA (above 10\%) occur. Most of the investigated systems with high polymer content showed volumetric phase ratios around 0.9. The volume of the bottom NaPA-rich phase is slightly larger than the top PEG-rich phase, which may indicate a certain salting-out effect of the PEG in the top phase. However, there are two points ( 8 and 9 ) where the ratio is quite different

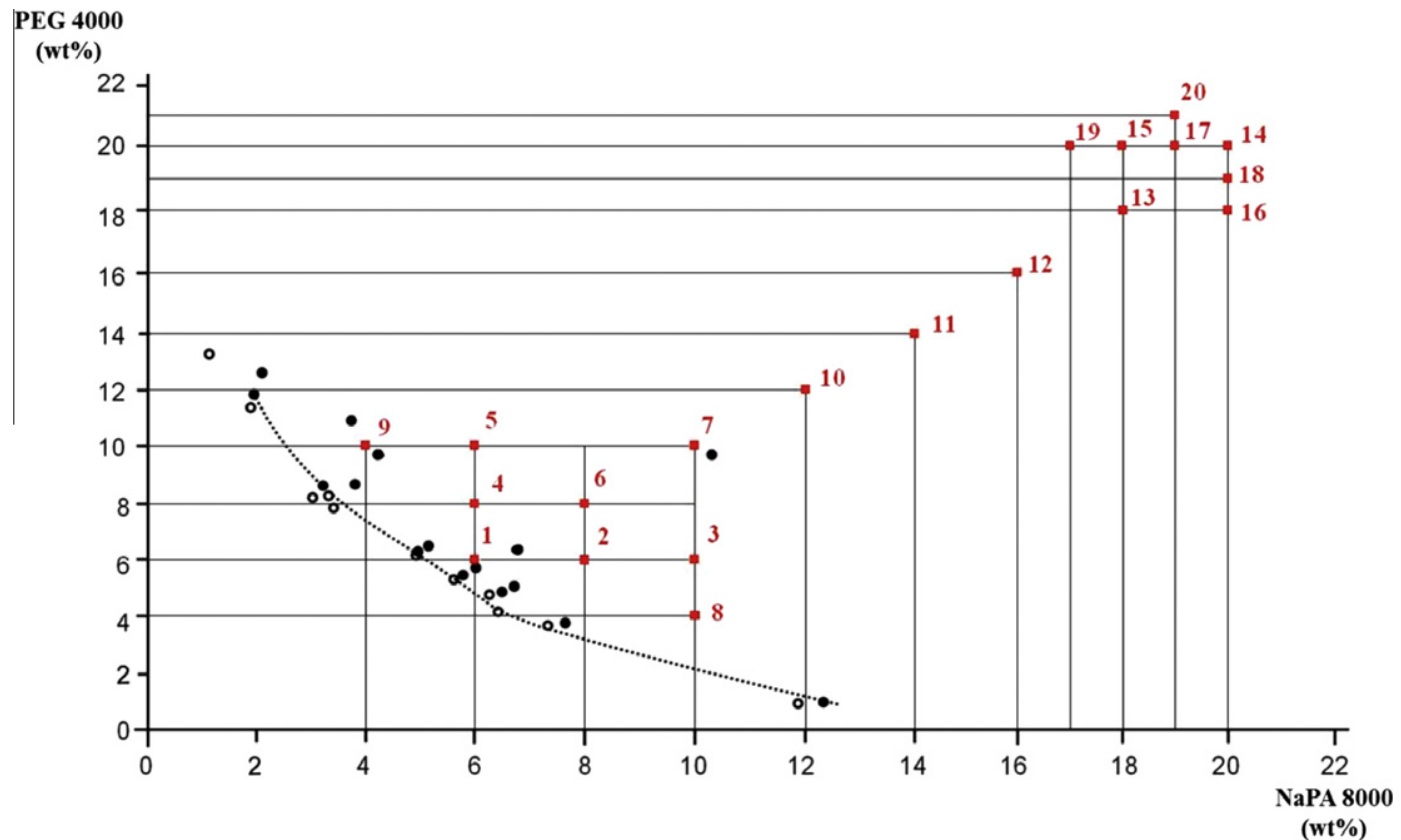

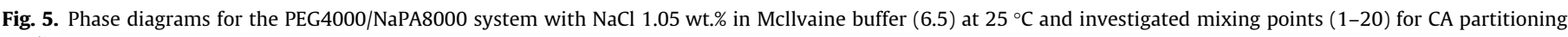
studies. 
Table 1

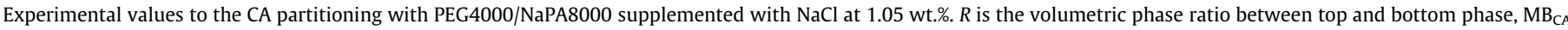

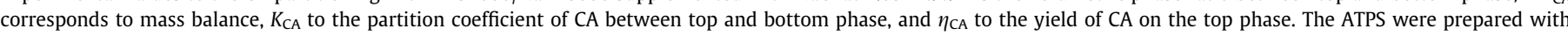
Mcllvaine buffer at $\mathrm{pH} 6.5$ at $25^{\circ} \mathrm{C}$.

\begin{tabular}{|c|c|c|c|c|c|c|}
\hline Extraction point & PEG4000 (wt.\%) & NaPA8000 (wt.\%) & $R$ & $\mathrm{MB}_{\mathrm{CA}}(\%)$ & $K_{\mathrm{CA}}$ & $\eta_{\mathrm{CA}}(\%)$ \\
\hline 1 & 6 & 6 & 1.11 & 99 & 1.46 & 61 \\
\hline 2 & 6 & 8 & 0.77 & 95 & 1.75 & 55 \\
\hline 3 & 6 & 10 & 0.53 & 95 & 2.05 & 50 \\
\hline 4 & 8 & 6 & 1.35 & 102 & 1.79 & 72 \\
\hline 5 & 10 & 6 & 1.66 & 100 & 2.05 & 78 \\
\hline 6 & 8 & 8 & 0.94 & 99 & 1.98 & 64 \\
\hline 7 & 10 & 10 & 0.90 & 99 & 2.48 & 68 \\
\hline 8 & 4 & 10 & 0.38 & 96 & 1.60 & 36 \\
\hline 9 & 10 & 4 & 3.59 & 97 & 1.53 & 82 \\
\hline 10 & 12 & 12 & 0.84 & 98 & 2.97 & 70 \\
\hline 11 & 14 & 14 & 0.91 & 96 & 3.62 & 74 \\
\hline 12 & 16 & 16 & 0.76 & 107 & 3.91 & 80 \\
\hline 13 & 18 & 18 & 0.78 & 107 & 4.68 & 84 \\
\hline 14 & 20 & 20 & $0.78 \pm 0.07$ & $100 \pm 1$ & $5.41 \pm 0.35$ & $81 \pm 1$ \\
\hline 15 & 20 & 18 & $0.81 \pm 0.09$ & $96 \pm 12$ & $5.83 \pm 0.37$ & $90 \pm 8$ \\
\hline 16 & 18 & 20 & $0.79 \pm 0.05$ & $99 \pm 4$ & $5.66 \pm 0.07$ & $74 \pm 9$ \\
\hline 17 & 20 & 19 & $0.84 \pm 0.00$ & $101 \pm 1$ & $5.44 \pm 0.31$ & $91 \pm 0$ \\
\hline 18 & 19 & 20 & $0.77 \pm 0.03$ & $93 \pm 3$ & $5.91 \pm 0.11$ & $80 \pm 7$ \\
\hline 19 & 20 & 17 & $0.79 \pm 0.09$ & $96 \pm 12$ & $4.71 \pm 0.28$ & $79 \pm 9$ \\
\hline 20 & 21 & 18 & $0.81 \pm 0.05$ & $97 \pm 7$ & $4.98 \pm 0.69$ & $81 \pm 5$ \\
\hline
\end{tabular}

from 1, which may be due to the large difference in polymer concentration (4 and $10 \mathrm{wt} . \%$ of PEG and/or NaPA). The CA partition coefficient and yield in top PEG-rich phase increase with the increase of polymer concentration in the system. The variation of polymers mass fraction and $K$-values are presented in Fig. 6 .

The maximum partition coefficient ( $K_{\mathrm{CA}}$, between 5 and 6 ) was obtained for polymers concentration range 18-20 wt.\%. As previously described, the salt type and concentration is the most important modulating factor for the partition, with both salting out effects and an electrochemical driving force on the CA partition to the PEG phase. It has been previously observed that the PEG-rich top phase contains more total polymer than the NaPA rich bottom phase [36]. This implies that the polyacrylate phase is entropically favored in terms of CA partitioning. Since CA in spite of this prefers the PEG-rich phase, the partitioning is strongly driven by effective enthalpic forces.

Fig. 6 also shows that an increase of polymeric concentration leads to a higher CA partition. It can be explained by the tie-line

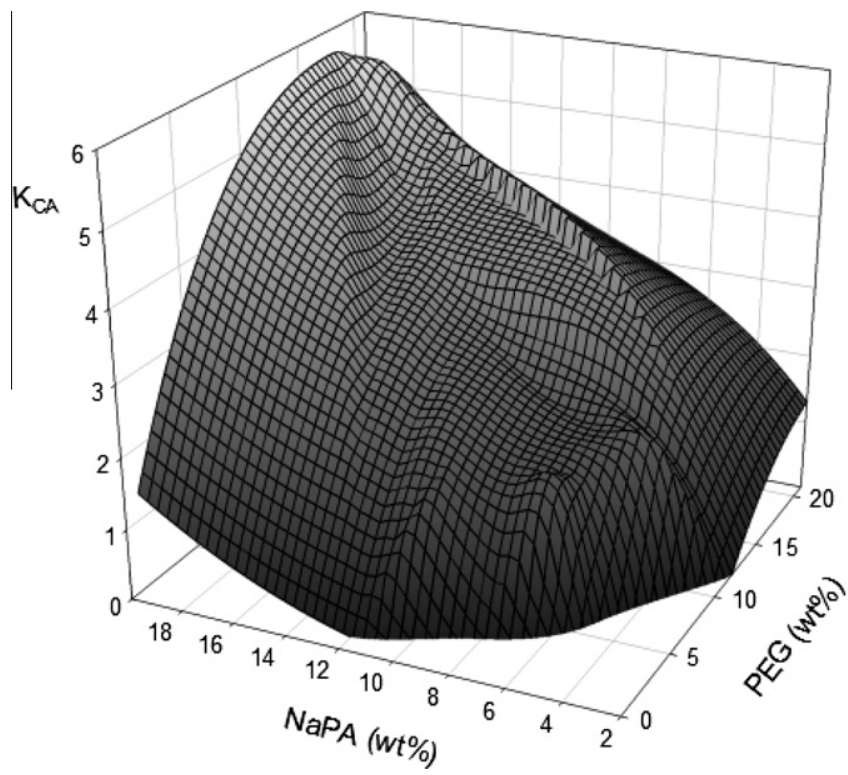

Fig. 6. Partition coefficients of CA as a function of PEG4000 and NaPA8000, with in ATPS containing with 1.05 wt.\% of $\mathrm{Na}_{2} \mathrm{SO}_{4}$, in Mcllvaine buffer ( $\mathrm{pH} \mathrm{6.5)}$ ) at $25^{\circ} \mathrm{C}$. length increase effect, since the difference between top and bottom-phase composition is the driving force for the increase on the partition.

This study allowed an optimization of the CA partitioning using the ATPS composed by PEG4000/NaPA8000/NaCl. The best values of CA partition were obtained for systems with higher polymer concentrations. Therefore, the point 14 with $20 \mathrm{wt} . \%$ of both polymers was chosen for further studies.

\subsection{CA partition with $\mathrm{PEG} / \mathrm{NaPA} / \mathrm{Na}_{2} \mathrm{SO}_{4}$ aqueous two-phase systems}

The same procedure used to PEG4000/NaPA8000/NaCl systems was applied for the systems PEG4000/ NaPA8000/ $/ \mathrm{Na}_{2} \mathrm{SO}_{4}$. The optimization of CA partition was done taking into account the phase diagrams described by Johansson et al. [36]. As in the case with $\mathrm{PEG} / \mathrm{NaPA} / \mathrm{NaCl}$ systems, the system mixing points were obtained by changing the mass fraction of both polymers. The selected experimental data and the respective phase diagram are presented in Fig. 7.

For all experimental points selected, the values of CA partition coefficient, mass balance, volumetric ratio and yield were measured and are presented in Table 2 . The systems with relatively low polymer content (points 1-4) show that an increase of the polymer concentrations leads to higher values of the CA partition coefficient. The points were chosen to obtain the highest $K_{\mathrm{CA}}$. Thus, a first investigation was performed (points 1-7), which showed that the NaPA influence on the CA extraction was higher than the PEG influence. Therefore a second series of experiments (7-13), with increasing NaPA concentration, was performed. However, the increase of NaPA concentration (points 11-13) caused precipitation of $\mathrm{Na}_{2} \mathrm{SO}_{4}$ and no partitioning data was evaluated for these systems. The mixing points with the highest partition coefficients $(6,8,9$ and 14$)$ were studied in triplicate.

No significant CA losses were observed, as confirmed by MB, all values being above or close to $90 \%$. The volume ratio was much lower than 1, demonstrating that CA was concentrated in the top PEG-rich phase. A higher volume of the NaPA-rich phase was explained by the salting-out of PEG, caused by both salt and polymer. The $\mathrm{Na}_{2} \mathrm{SO}_{4}$ has a strong effective repulsion to PEG and partitions more to the bottom NaPA-rich phase, increasing its volume. The highest yield values were obtained for the systems with higher concentration of PEG (10 wt.\%). The highest values of $K_{\mathrm{CA}}$ were 


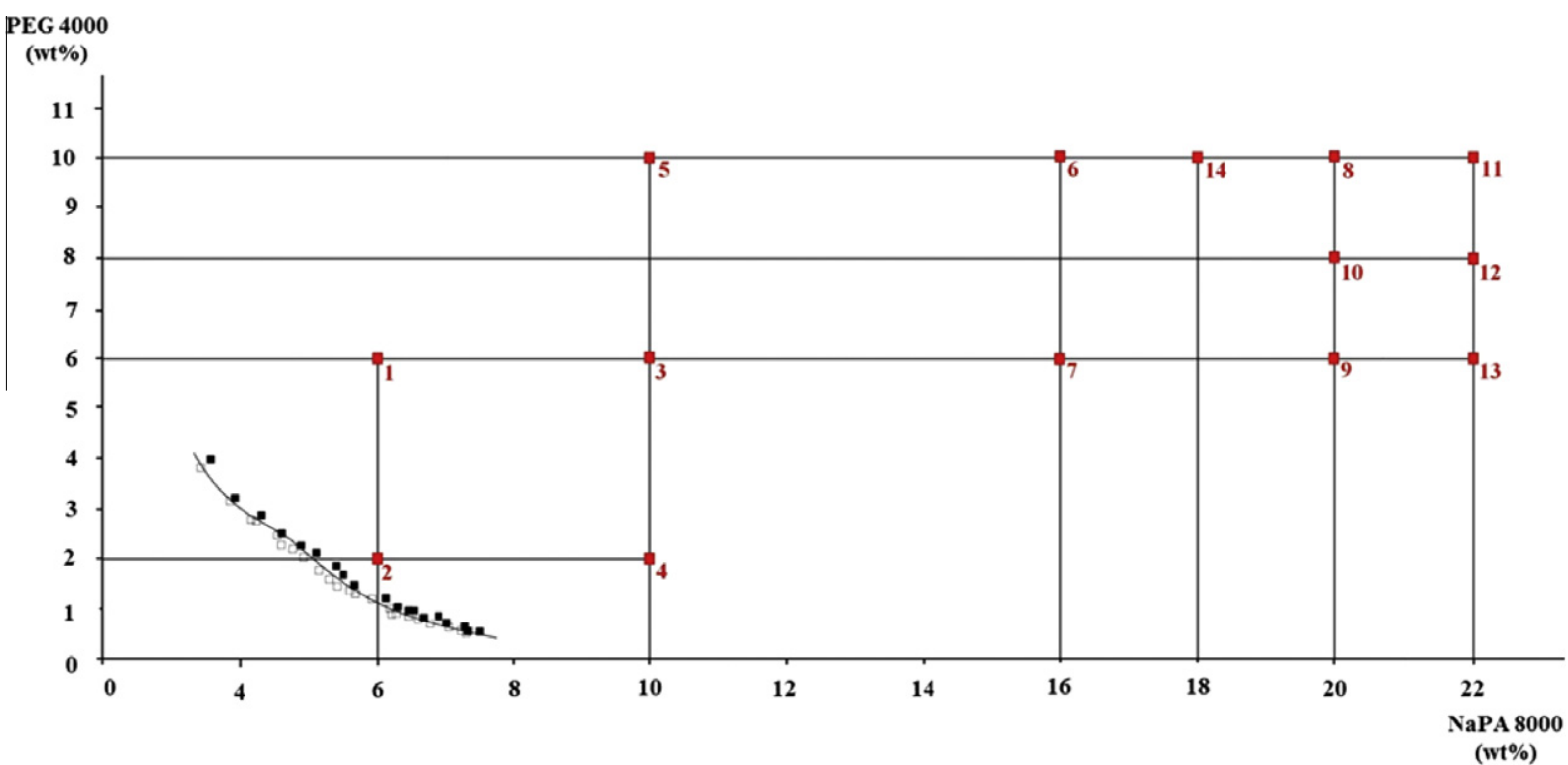

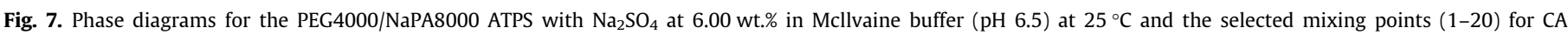
partitioning studies.

Table 2

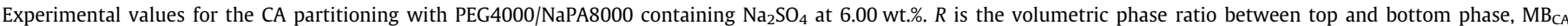

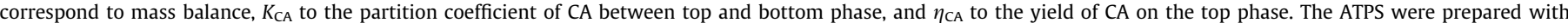
Mcllvaine buffer at $\mathrm{pH} 6.5$ at $25^{\circ} \mathrm{C}$.

\begin{tabular}{|c|c|c|c|c|c|c|}
\hline Extraction point & PEG4000 (wt.\%) & NaPA8000 (wt.\%) & $R$ & $\mathrm{MB}_{\mathrm{CA}}(\%)$ & $K_{\mathrm{CA}}$ & $\eta_{\mathrm{CA}}(\%)$ \\
\hline 1 & 6 & 6 & 0.39 & 104 & 1.69 & 41 \\
\hline 2 & 2 & 6 & 0.07 & 103 & 1.25 & 8 \\
\hline 3 & 6 & 10 & 0.24 & 93 & 3.06 & 39 \\
\hline 4 & 2 & 10 & 0.07 & 93 & 1.93 & 12 \\
\hline 5 & 10 & 10 & 0.42 & 96 & 3.65 & 58 \\
\hline 6 & 10 & 16 & $0.32 \pm 0.02$ & $98 \pm 16$ & $7.15 \pm 0.41$ & $68 \pm 9$ \\
\hline 7 & 6 & 16 & 0.18 & 102 & 6.27 & 54 \\
\hline 8 & 10 & 20 & $0.26 \pm 0.00$ & $90 \pm 8$ & $11.91 \pm 2.08$ & $68 \pm 9$ \\
\hline 9 & 6 & 20 & $0.14 \pm 0.00$ & $90 \pm 11$ & $9.03 \pm 2.41$ & $50 \pm 11$ \\
\hline 10 & 8 & 20 & $0.21 \pm 0.02$ & $85 \pm 2$ & $8.59 \pm 0.17$ & $55 \pm 4$ \\
\hline 14 & 10 & 18 & $0.29 \pm 0.01$ & $89 \pm 2$ & $8.14 \pm 2.19$ & $63 \pm 3$ \\
\hline
\end{tabular}

obtained for the higher concentrations of both polymers, following the behavior observed with the PEG/NaPA/NaCl systems, described previously. The $K_{\mathrm{CA}}$ values are presented in detail in Fig. 8.

Fig. 8 shows that the highest value for the CA partition was obtained for the system with 10 and $20 \mathrm{wt} . \%$ concentrations of PEG4000 and NaPA8000, respectively. It is also demonstrated that the NaPA influence on the CA partitioning is higher than the PEG influence. Previous studies of negatively charged hemoglobin partition [24] and GFP [21] have shown that $\mathrm{Na}_{2} \mathrm{SO}_{4}$ favors the partition of negatively charged protein to the PEG-rich phase, and it also was demonstrated that this behavior was more pronounced in systems with $\mathrm{Na}_{2} \mathrm{SO}_{4}$ than $\mathrm{NaCl}$. Also it is known that NaPA is strongly negative, presenting a strong repulsive interaction with negatively charged biomolecules (such as CA). Thus, the combination of both factors explains the higher values of $K_{\mathrm{CA}}$ obtained with the increase of NaPA concentration.

\subsection{Comparison of optimized PEG4000/NaPA8000 aqueous two-phase systems}

The optimization of the CA partitioning shows that the highest partitioning of CA was obtained for the systems with higher concentrations of both polymers. With 6 wt.\% of $\mathrm{Na}_{2} \mathrm{SO}_{4}$, the highest partition coefficient was obtained in systems having 10 and

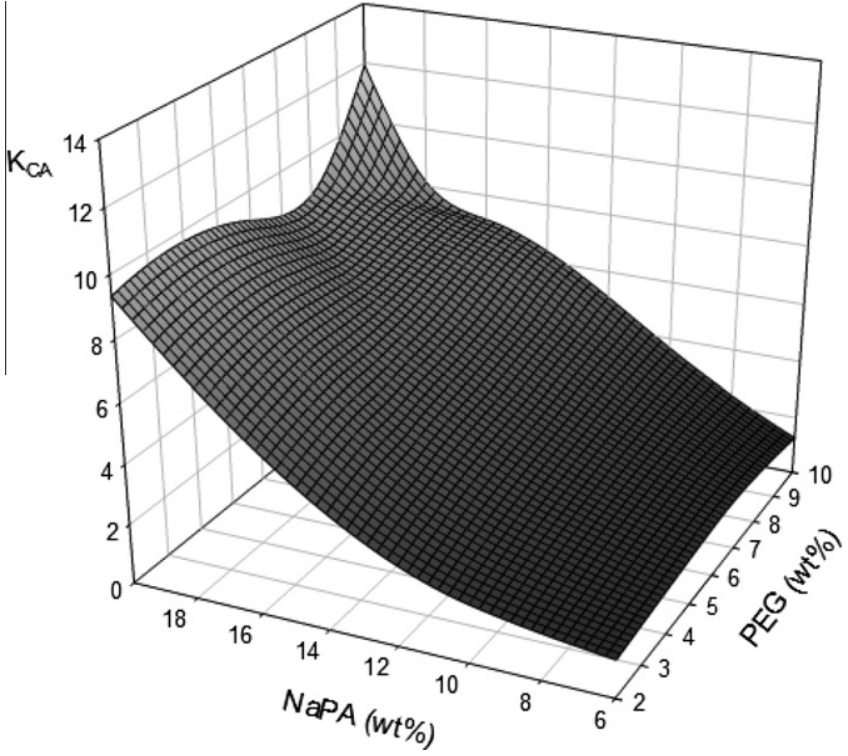

Fig. 8. Partition coefficients of CA as a function of PEG 4000 and NaPA 8000, in ATPS containing 6.00 wt.\% of $\mathrm{Na}_{2} \mathrm{SO}_{4}$, in Mcllvaine buffer (pH 6.5) at $25^{\circ} \mathrm{C}$. 
Table 3

Experimental values to the conductivity, $\mathrm{pH}$ and viscosity of PEG and NaPA-rich phase after separation. The ATPS were prepared with Mcllvaine buffer at pH 6.5 at $25^{\circ} \mathrm{C}$.

\begin{tabular}{|c|c|c|c|c|}
\hline PEG4000/NaPA8000/salt system (wt.\%) & Phase & Conductivity $\left(\mathrm{mS} \mathrm{cm}^{-1}\right)$ & $\mathrm{pH}$ & Viscosity (mPa s) \\
\hline \multirow[t]{2}{*}{$20 / 20 / 1.05 \mathrm{NaCl}$} & PEG & 0.11 & 7.34 & 119.0 \\
\hline & $\mathrm{NaPA}$ & 3.6 & 6.92 & 76.98 \\
\hline \multirow[t]{2}{*}{$10 / 20 / 6.00 \mathrm{Na}_{2} \mathrm{SO}_{4}$} & PEG & 0.46 & 6.78 & 151.1 \\
\hline & $\mathrm{NaPA}$ & 3.2 & 6.70 & 107.1 \\
\hline
\end{tabular}

Table 4

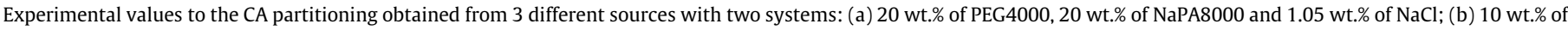

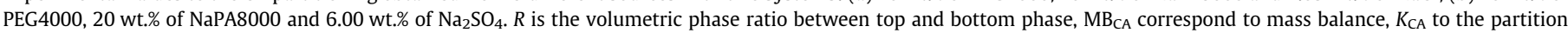
coefficient of CA between top and bottom phase, and $\eta_{\mathrm{CA}}$ to the yield of CA on the top phase. The ATPS were prepared with Mcllvaine buffer at pH 6.5 at $25{ }^{\circ} \mathrm{C}$.

\begin{tabular}{|c|c|c|c|c|c|}
\hline CA sources & System & $R$ & $\mathrm{MB}_{\mathrm{CA}}(\%)$ & $K_{\mathrm{CA}}$ & $\eta_{\mathrm{CA}}(\%)$ \\
\hline Commercial & $\begin{array}{l}a \\
b\end{array}$ & $\begin{array}{l}0.78 \pm 0.07 \\
0.26 \pm 0.00\end{array}$ & $\begin{array}{r}100 \pm 1 \\
90 \pm 8\end{array}$ & $\begin{array}{r}5.41 \pm 0.35 \\
11.91 \pm 2.08\end{array}$ & $\begin{array}{l}81 \pm 1 \\
68 \pm 9\end{array}$ \\
\hline Pure & $\begin{array}{l}a \\
b\end{array}$ & $\begin{array}{l}0.75 \pm 0.09 \\
0.25 \pm 0.03\end{array}$ & $\begin{array}{l}88 \pm 6 \\
93 \pm 4\end{array}$ & $\begin{array}{r}5.91 \pm 0.75 \\
10.56 \pm 2.86\end{array}$ & $\begin{array}{l}72 \pm 5 \\
68 \pm 7\end{array}$ \\
\hline $\begin{array}{l}\text { Fermented } \\
\text { Broth }\end{array}$ & $\begin{array}{l}a \\
b\end{array}$ & $\begin{array}{l}- \\
0.24 \pm 0.02\end{array}$ & - & ${ }^{-}-15 \pm 1.06$ & $\begin{array}{l}- \\
55 \pm 5\end{array}$ \\
\hline
\end{tabular}

20 wt.\% of PEG and NaPA, respectively. The highest $K_{\mathrm{CA}}$ of the systems with $1.05 \mathrm{wt} . \% \mathrm{NaCl}$ was obtained with $20 \mathrm{wt} . \%$ of both polymers. For both polymeric aqueous systems the volume ratio is less than 1, indicating that PEG phase has a minor volume as compared with NaPA phase. Analyzing the values of $K_{\mathrm{CA}}$ for both systems with commercial CA, it is observed that the CA partition obtained with $\mathrm{Na}_{2} \mathrm{SO}_{4}$ is twice the value in the system with $\mathrm{NaCl}$. The entropic driving force cannot play an important role for CA-partitioning since CA partitions to the PEG-rich phase, in spite of this phase being more concentrated in polymer. In order to understand the forces that drive the CA partition behavior, the conductivity, $\mathrm{pH}$ and viscosity of each phase after the separation were analyzed. A summary with respective parameters is presented in Table 3.

The low values of electrical conductivity and the higher viscosity in the PEG-rich phase indicate a large phase difference in total salt and polymer concentration. These values are in agreement with data by Johansson et al. $[21,24,36]$. The data indicates that the PEG-rich phase contains more total polymer than the bottom phase. Since CA is a small molecule (molecular size $199 \mathrm{Da}$ ) it is only weakly affected by the entropic exclusion effect. The results indicate that the hydrophobic, electrochemical and electrostatic interactions drive the partition of Clavulanic Acid to the PEG-rich phase.

\subsection{Partition studies with pure CA pure and in the fermented broth}

The systems with highest CA recovery (using commercial CA from Galena) were selected for the studies with pure CA solution (obtained from Sigma-Aldrich) and with CA from fermented broth of $S$. clavuligerus. The corresponding systems (concentrations described before) were prepared and the values of partition coefficient, yield phase, mass balance and volume ratio of CA measured and presented in Table 4.

The comparison of the values obtained from different sources shows that CA from a commercial source can be applied as an alternative to a pure solution (more expensive) to carry out extensive studies of CA partition for both systems, since most of the values obtained with the two different sources were similar. Data obtained from fermented broth of $S$. clavuligerus show that system supplemented with $\mathrm{Na}_{2} \mathrm{SO}_{4}$ can be effective to promote CA partitioning $\left(K_{\mathrm{CA}}=9.15 \pm 1.06\right)$. On the other hand, the PEG/NaPA system supplemented with $\mathrm{NaCl}$ was not effective in CA partition, since most of the system mass formed an inter-phase (approxi- mately $6 \mathrm{~mL}$ ). The top-phase was relatively small $(2 \mathrm{~mL})$ and the bottom phase was almost nonexistent (lower than $0.5 \mathrm{~mL}$ ). Thus, its quantification was impossible as well as the calculation of the parameters under study. As described by Johansson et al. [24], in PEG/NaPA systems a minimum concentration of salt is necessary to promote the phase separation. However in a fermented broth there are many proteins, cell-debris, and other amphiphilic impurities that interact both with PEG and the more hydrophilic NaPA-polymer. If the top-bottom phase difference is small the homogenate will tend to form a large inter-phase. In order to achieve an effective phase separation with a more compact interphase of homogenate a higher concentration of salt is necessary. Thus, the low concentration of $\mathrm{NaCl}$ (1.05 wt.\%) may explain the poor separation observed. Previous studies [24] using hemoglobin in high concentrations also led to precipitate formation in the $\mathrm{NaPA} / \mathrm{PEG}$ systems with salt $\left(\mathrm{NaCl}\right.$ or $\left.\mathrm{Na}_{2} \mathrm{SO}_{4}\right)$.

The $\mathrm{Na}_{2} \mathrm{SO}_{4}$ containing systems showed an interesting CA partition coefficient $\left(K_{\mathrm{CA}}=9.15 \pm 1.06\right)$. This value was higher than the one observed in an earlier study $[4,38]$ of CA purification using two different aqueous two-phase micellar systems composed by the surfactants $n$-decyltetraethylene oxide and dodecylmethylamine oxide, and surfactant Triton $\mathrm{X}-114$ and the anionic one AOT, where the highest values of $K_{\mathrm{CA}}$ were 0.94 and 1.48 , respectively. A high partition coefficient $\left(K_{\mathrm{CA}}=8.2\right)$ was obtained in a previous CA fermentative extraction study [39] using PEG and phosphate salts. Thus the PEG4000/NaPA8000/ $\mathrm{Na}_{2} \mathrm{SO}_{4}$ system seems to be advantageous for recovering the antibiotic and carry out a preliminary CA purification.

In order to evaluate the purification of CA in respect to the total proteins in the fermented broth, a comparison between the partition coefficients of CA and proteins was performed. Thus, for the best PEG4000/NaPA8000 system which also contained $\mathrm{Na}_{2} \mathrm{SO}_{4}$, the total protein content was determined through the BCA method [40]. The protein partition coefficient $\left(K_{P}=8.82 \pm 1.97\right)$ shows that the proteins present in the fermented broth are preferentially concentrated into PEG-rich phase, altogether with the CA $\left(K_{\mathrm{CA}}=9.15 \pm 1.06\right)$. Ideally, in a purification process, proteins should partition opposite to the CA. Johansson et al. [24] showed that the proteins can partition in PEG/NaPA aqueous systems to both phases, depending on the system used and the respective properties (such as, $\mathrm{pH}$, polymer concentration, polymer molecular weight, salt concentration or type of salt). Hemoglobin can be partitioned to the top or bottom phase depending of type of salt used 
( $\mathrm{NaCl}$ or $\mathrm{Na}_{2} \mathrm{SO}_{4}$ ) and $\mathrm{pH}$, while lysozyme partitions preferentially to the PEG-rich phase, and G6PDH partitions to the NaPA-rich phase. In another work of Johansson [21], the green fluorescent protein in a similar system (PEG4000/NaPA8000/ $\mathrm{Na}_{2} \mathrm{SO}_{4}$ ) partitions also to the PEG-rich phase ( $K=3.5)$ with low concentrations of salt ( 3 wt.\%) and the partitioning decreases $(K=2.5)$ with higher salt concentrations (6 wt.\%). Despite the lower purification capacity of these systems, and supported by the results reported in literature, it is possible to conclude that the purification capacity can be improved by the optimization of the aqueous systems conditions already mentioned, namely concentration of salt and/or polymers.

The requirement of medical products with higher purity levels demands that the processes for biomolecules purifications from fermented broth have many steps, increasing the respective costs. Thus, the PEG/NaPA polymer aqueous two-phase system can be of interest for capturing CA in an initial step of the purification process. The polymers are non-toxic, inert, commercially available and relatively inexpensive.

\section{Conclusions}

The stability and partition of CA in the PEG/NaPA aqueous twophase systems was studied. It was verified that $C A$ is stable in presence of both PEG and NaPA and low salt concentrations. All the partitions studies show that the antibiotic preferentially partitions to the PEG-rich (top) phase ( $\left.K_{\mathrm{CA}}>1\right)$. The results demonstrate that enthalpic interactions are the major driving forces of partition (in contrast to entropic repulsion). High partition coefficient (above 11) was obtained for the system with $10 \mathrm{wt} . \%$ of PEG4000, 20 wt.\% of NaPA8000 and 6 wt.\% of $\mathrm{Na}_{2} \mathrm{SO}_{4}$ with a commercial source. A similar partition coefficient (above 10) was achieved from CA obtained from fermented broth. The results presented in this work show the potential of using PEG/NaPA ATPS as a new initial step for CA recovery and purification.

\section{Acknowledgements}

Financial support is gratefully acknowledged from FAPESP (Fundação de Amparo à Pesquisa do Estado de São Paulo, São Paulo, Brazil) and from CNPq (National Council for Scientific and Technological Development, Brasília, Brazil) and CAPES (Coordenação de Aperfeiçoamento de Pessoal de Nível Superior).

\section{References}

[1] C. Reading, M. Cole, Clavulanic acid - beta-lactamase-inhibiting beta-lactam from Streptomyces clavuligerus, Antimicrob. Agents Chemother. 11 (1977) 852 857.

[2] P.S. Saudagar, S.A. Survase, R.S. Singhal, Clavulanic acid: a review, Biotechnol. Adv. 26 (2008) 335-351.

[3] D.A.V. Marques, R.P.S. Oliveira, P. Perego, A.L.F. Porto, A. Pessoa, A. Converti, Kinetic and thermodynamic investigation on clavulanic acid formation and degradation during glycerol fermentation by Streptomyces DAUFPE 3060 Enzyme Microbiol. Technol. 45 (2009) 169-173.

[4] V.C. Santos, F.A. Hasmann, A. Converti, A. Pessoa, Liquid-liquid extraction by mixed micellar systems: a new approach for clavulanic acid recovery from fermented broth, Biochem. Eng. J. 56 (2011) 75-83.

[5] M. Watve, V. Shejval, C. Sonawane, M. Rahalkar, A. Matapurkar, Y. Shouche, M. Patole, N. Phadnis, A. Champhenkar, K. Damle, S. Karandikar, V. Kshirsagar, M. Jog, The ' $K$ ' selected oligophilic bacteria: a key to uncultured diversity?, Curr Sci. India 78 (2000) 1535-1542.

[6] D.J. Kim, J.A. King, L. Zuccarelli, C.F. Ferris, G.A. Koppel, C.T. Snowdon, C.H. Ahn, Clavulanic acid: a competitive inhibitor of beta-lactamases with novel anxiolytic-like activity and minimal side effects, Pharmacol. Biochem. Behav. 93 (2009) 112-120.

[7] G.C. Kost, S. Selvaraj, Y.B. Lee, D.J. Kim, C.H. Ahn, B.B. Singh, Clavulanic acid increases dopamine release in neuronal cells through a mechanism involving enhanced vesicle trafficking, Neurosci. Lett. 504 (2011) 170-175

[8] Y. Huh, M.S. Ju, H. Park, S. Han, Y.M. Bang, C.F. Ferris, G.A. Koppe, J.A. King, M.L Kim, D.J. Kim, C.H. Ahn, M.S. Oh, Clavulanic acid protects neurons in pharmacological models of neurodegenerative diseases, Drug Dev. Res. 71 (2010) 351-357.
[9] M. Videira, M.R. Airesbarros, Liquid-liquid-extraction of clavulanic acid using an aqueous 2-phase system of polyethylene-glycol and potassium phosphate, J. Chromatogr. A 668 (1994) 237-240.

[10] M. Barboza, R.M.R.G. Almeida, C.O. Hokka, Kinetic studies of clavulanic acid recovery by ion exchange chromatography, Bioseparation 10 (2001) 221-227.

[11] P.A.J. Rosa, I.F. Ferreira, A.M. Azevedo, M.R. Aires-Barros, Aqueous two-phase systems: a viable platform in the manufacturing of biopharmaceuticals, J. Chromatogr. A 1217 (2010) 2296-2305.

[12] P.G. Mazzola, A.M. Lopes, F.A. Hasmann, A.F. Jozala, T.C.V. Penna, P.O Magalhaes, C.O. Rangel-Yagui, A. Pessoa, Liquid-liquid extraction of biomolecules: an overview and update of the main techniques, J. Chem. Technol. Biotechnol. 83 (2008) 143-157.

[13] B. Bolognese, B. Nerli, G.N. Pico, Application of the aqueous two-phase systems of ethylene and propylene oxide copolymer-maltodextrin for protein purification, J. Chromatogr. B Anal. 814 (2005) 347-353.

[14] X.C. Chen, G.M. Xu, X. Li, Z.J. Li, H.J. Ying, Purification of an alpha-amylase inhibitor in a polyethylene glycol fructose-1,6-bisphosphate trisodium salt aqueous two-phase system, Process Biochem. 43 (2008) 765-768.

[15] M.M. Bora, S. Borthakur, P.C. Rao, N.N. Dutta, Aqueous two-phase partitioning of cephalosporin antibiotics: effect of solute chemical nature, Sep. Purif. Technol. 45 (2005) 153-156.

[16] J. Persson, H.O. Johansson, I. Galaev, B. Mattiasson, F. Tjerneld, Aqueous polymer two-phase systems formed by new thermoseparating polymers, Bioseparation 9 (2000) 105-116.

[17] I.Y. Galaev, I. Galaev, B. Mattiasson, Smart Polymers for Bioseparation and Bioprocessing, Taylor \& Francis, 2002.

[18] P.Å. Albertsson, Partition of Cell Particles and Macromolecules: Separation and Purification of Biomolecules, Cell Organelles, Membranes, and Cells in Aqueous Polymer Two-Phase systems and Their Use in Biochemical Analysis and Biotechnology, third ed., Wiley, New York, 1986.

[19] D.Q. Lin, Y.T. Wu, L.H. Mel, Z.Q. Zhu, S.J. Yao, Modeling the protein partitioning in aqueous polymer two-phase systems: influence of polymer concentration and molecular weight, Chem. Eng. Sci. 58 (2003) 2963-2972.

[20] V.C. Santos, J.F.B. Pereira, R.B. Haga, C.O. Rangel-Yagui, J.A.C. Teixeira, A. Converti, A. Pessoa, Stability of clavulanic acid under variable $\mathrm{pH}$, ionic strength and temperature conditions a new kinetic approach, Biochem. Eng. J. 45 (2009) 89-93.

[21] H.O. Johansson, M. Ishii, M. Minaguti, E. Feitosa, T.C.V. Penna, A. Pessoa, Separation and partitioning of green fluorescent protein from Escherichia coli homogenate in poly(ethylene glycol)/sodium-poly(acrylate) aqueous twophase systems, Sep. Purif. Technol. 62 (2008) 166-174.

[22] V. Gupta, S. Nath, S. Chand, Role of water structure on phase separation in polyelectrolyte-polyethyleneglycol based aqueous two-phase systems, Polymer 43 (2002) 3387-3390.

[23] S. Saravanan, J.A. Reena, J.R. Rao, T. Murugesan, B.U. Nair, Phase equilibrium compositions, densities, and viscosities of aqueous two-phase poly(ethylene glycol) plus poly(acrylic acid) system at various temperatures, J. Chem. Eng. Data 51 (2006) 1246-1249.

[24] H.O. Johansson, F.M. Magaldi, E. Feitosa, A. Pessoa, Protein partitioning in poly(ethylene glycol)/sodium polyacrylate aqueous two-phase systems, J. Chromatogr. A 1178 (2008) 145-153.

[25] M. Barboza, C. Silva, M. Cuel, V. Barreto, C.O. Hokka, Separation of clavulanic acid from fermented broth of amino acids by an aqueous two-phase system and ion exchange adsorption, New Biotechnol. 25 (2009) S181.

[26] C.S. Silva, E. Bovarotti, M.I. Rodrigues, C.O. Hokka, M. Barboza, Evaluation of the effects of the parameters involved in the purification of clavulanic acid from fermentation broth by aqueous two-phase systems, Bioprocess. Biosyst. Eng. 32 (2009) 625-632.

[27] S.C.A. Ortiz, C.O. Hokka, A.C. Badino, Utilization of soybean derivatives on clavulanic acid production by Streptomyces clavuligerus, Enzyme Microb. Technol. 40 (2007) 1071-1077.

[28] A.E. Bird, J.M. Bellis, B.C. Gasson, Spectrophotometric assay of clavulanic acid by reaction with imidazole, Analyst 107 (1982) 1241-1245.

[29] J. Haginaka, T. Nakagawa, T. Uno, Stability of clavulanic acid in aqueoussolutions, Chem. Pharm. Bull. 29 (1981) 3334-3341.

[30] A.F. Mayer, W.D. Deckwer, Simultaneous production and decomposition of clavulanic acid during Streptomyces clavuligerus cultivations, Appl. Microbiol. Biotechnol. 45 (1996) 41-46.

[31] J.A. Roubos, P. Krabben, W.T.A.M. de Laat, R. Babuska, J.J. Heijnen, Clavulanic acid degradation in Streptomyces clavuligerus fed-batch cultivations, Biotechnol. Prog. 18 (2002) 451-457.

[32] H.C. Lynch, Y. Yang, Degradation products of clavulanic acid promote clavulanic acid production in cultures of Streptomyces clavuligerus, Enzyme Microbiol. Technol. 34 (2004) 48-54.

[33] P.A. Bersanetti, R.M.R.G. Almeida, M. Barboza, M.L.G. Araujo, C.O. Hokka, Kinetic studies on clavulanic acid degradation, Biochem. Eng. J. 23 (2005) 3136.

[34] J. Li, W.J. Kao, Synthesis of polyethylene glycol (PEG) derivatives and PEGylated-peptide blopolymer conjugates, Biomacromolecules 4 (2003) 1055-1067.

[35] P. Hughes, C.R. Lowe, Purification of proteins by aqueous 2-phase partition in novel acrylic co-polymer systems, Enzyme Microbiol. Technol. 10 (1988) 115122.

[36] H.-O. Johansson, E. Feitosa, A.P. Junior, Phase diagrams of the aqueous twophase systems of poly(ethylene glycol)/sodium polyacrylate/salts, Polymers 3 (2011) 587-601. 
[37] M. Jonsson, H.O. Johansson, Protein partitioning in thermoseparating systems of a charged hydrophobically modified ethylene oxide polymer, J. Chromatogr. A 983 (2003) 133-144.

[38] E.G. de Andrade, M.D.C. Silva, R.B. Haga, V.C. Santos, A. Pessoa, C.D. RangelYagui, Extraction of clavulanic acid using aqueous two-phase micellar system, Biotechnol. Appl. Bioc. 58 (2011) 103-108.
[39] D.A.V. Marques, A. Pessoa, J.L. Lima, A. Converti, P. Perego, A.L.F. Porto, Extractive fermentation of clavulanic acid by Streptomyces DAUFPE 3060 using aqueous two-phase system, Biotechnol. Prog. 27 (2011) 95-103.

[40] P.K. Smith, R.I. Krohn, G.T. Hermanson, A.K. Mallia, F.H. Gartner, M.D. Provenzano, E.K. Fujimoto, N.M. Goeke, B.J. Olson, D.C. Klenk, Measurement of protein using bicinchoninic acid, Anal. Biochem. 150 (1985) 76-85. 